\title{
Work-up of globus : assessing the benefits of neck ultrasound and videofluorography
}

\section{Järvenpää, Pia}

2017-02

Järvenpää , P , Ilmarinen , T , Geneid , A , Pietarinen , P , Kinnari , T J , Rihkanen , H , Ruohoalho, J , Markkanen-Leppänen , M , Bäck , L \& Arkkila , P 2017 , ' Work-up of globus : assessing the benefits of neck ultrasound and videofluorography ', European Archives of Oto-Rhino-Laryngology , vol. 274 , no. 2 , pp. 931-937 . https://doi.org/10.1007/s00405-016-4307-8

http://hdl.handle.net/10138/234199

https://doi.org/10.1007/s00405-016-4307-8

unspecified

publishedVersion

Downloaded from Helda, University of Helsinki institutional repository.

This is an electronic reprint of the original article.

This reprint may differ from the original in pagination and typographic detail.

Please cite the original version. 


\title{
Work-up of globus: assessing the benefits of neck ultrasound and videofluorography
}

\author{
Pia Järvenpää ${ }^{1}$ - Taru Ilmarinen ${ }^{1} \cdot$ Ahmed Geneid $^{1} \cdot$ Petra Pietarinen $^{1}$ \\ Teemu J. Kinnari ${ }^{1} \cdot$ Heikki Rihkanen ${ }^{1} \cdot$ Johanna Ruohoalho $^{1} \cdot$ Mari Markkanen- \\ Leppänen $^{1} \cdot$ Leif Bäck $^{1} \cdot$ Perttu Arkkila $^{2}$ Leena-Maija Aaltonen ${ }^{1}$
}

Received: 15 July 2016/Accepted: 12 September 2016/Published online: 17 September 2016

(c) Springer-Verlag Berlin Heidelberg 2016

\begin{abstract}
Globus patients with normal ear, nose, and throat (ENT) status are a diagnostic challenge. The symptom may be long lasting and cause concern about malignancy, leading to possibly unnecessary further investigation. The aim of the study was to assess whether radiological examinations are useful in globus diagnostics, how often patients suffer from persistent globus, and whether globus patients with normal ENT status develop a malignancy during a follow-up. We reviewed medical records of all 76 globus patients referred to Helsinki University Hospital, Department of Otorhinolaryngology-Head and Neck Surgery in 2009. Patient history and findings in physical and radiological examinations were registered. A questionnaire concerning patients' present pharyngeal symptoms was sent 3 and 6 years after their initial visit. Data from the Finnish Cancer Registry revealed whether patients developed malignancies within a 3-year follow-up. Based on medical records, neck ultrasound was performed for 37 (49\%) and videofluorography for 22 patients (29\%), with nonsignificant findings. After a 3- and 6-year follow-up, half patients indicated that they were asymptomatic or had fewer symptoms, whereas the rest had persistent symptoms. The Finnish Cancer Registry data confirmed that globus patients developed no head and neck malignancies during a 3-year follow-up. In the present study, neck ultrasound and videofluorography showed no additional
\end{abstract}

Pia Järvenpää

pia.jarvenpaa@fimnet.fi

1 Department of Otorhinolaryngology - Head and Neck Surgery, University of Helsinki and Helsinki University Hospital, P.O. Box 263, FI-00029 HUS Helsinki, Finland

2 Department of Gastroenterology, University of Helsinki and Helsinki University Hospital, Helsinki, Finland benefit to evaluate the globus etiology in patients whose ENT status was normal. Half the globus patients suffered from persistent symptoms after a 3- and 6-year follow-up, indicating that globus may cause discomfort chronically. However, no patients developed malignancies during a 3-year follow-up.

Keywords Globus · Malignancy · Globus diagnostics · Follow-up

\section{Introduction}

Globus, was already recognized at the time of Hippocrates. Historically, it has been considered a hysterical symptom occurring especially in women. Up to age 50, women are three times as likely to be affected, as are men [1]. Although, women seek help more easily, the symptom affects both genders [2]. Patients often describe globus sensation in various ways, such as feeling of a lump, a foreign body or tightness in the throat [3].

The etiology of globus is controversial, but presumably it has various causes. However, it has been recently shown, that gastroesophageal reflux disease (GERD) without reflux symptoms is not a cause for globus [4]. Elevated upper esophageal sphincter (UES) pressure has been suggested to play a role, but recent findings are contradictory $[4,5]$. In addition, some causes may be psychological and involve stress [6].

Because the underlying causes are unclear, a strategy for patient examination is still lacking. For a typical globus symptom, an outpatient examination is considered sufficient without any further investigation, [7] but many globus patients still undergo radiological examinations. Globus may raise concern about malignancy, and it may be a 
challenge to assure both the ear, nose, and throat (ENT) physician and the patient that further investigations are unnecessary. However, globus patients with other symptoms such as dysphagia, food sticking in the throat, or weight loss require further investigation to exclude malignancy [7]. Although the globus symptom may be persistent, its treatment often focuses on explaining the symptom's benign nature [2].

The aim of this study was to investigate whether radiological examinations such as neck ultrasound or videofluorography prove etiologically useful in globus diagnostics when clinical ENT status is normal. We also investigated whether any patient developed malignancy, with data from the Finnish Cancer Registry. To survey the persistence of globus symptom during a long follow-up, we sent a questionnaire 3 and 6 years after the initial visit.

\section{Materials and methods}

\section{Subjects}

All 76 patients referred to Helsinki University Hospital, Department of Otorhinolaryngology-Head and Neck Surgery, in 2009 because of globus, were drawn from the hospital database using the International Statistical Classification of Diseases 10th edition (ICD-10) code F45.8. This code is generally used in our clinic for globus. Diagnoses were confirmed by reviewing the medical data. Globus patients' previous medical history and findings on physical and radiological examinations were registered. The ENT physician's opinion on the suspected cause for globus was reviewed. Data from the Finnish Cancer Registry, which has maintained a nationwide database on all cancer cases since 1953, were surveyed to reveal all malignancies diagnosed within 3 years after the initial visit.

\section{Patient surveys}

Of these 76 patients, 6 were excluded from the survey: 1 patient was deceased, 2 had no contact information, and 3 had a native language other than Finnish or Swedish, which are official languages in Finland. Thus, 70 patients $(\mathrm{m} /$ $\mathrm{f}=24 \% / 76 \%)$ received the questionnaire in December 2012, and if the patient did not reply initially, again in February 2013. The questionnaire inquired the subjective outcome with a single question whether patients were asymptomatic, had fewer or more symptoms, or experienced their symptoms as the same. In addition, the questionnaire included the Deglutition Handicap Index (DHI) (Table 1), translated into Finnish and Swedish to evaluate patients' current pharyngeal symptoms quantitatively. In the DHI, 20 points or more is considered to show abnormality [8]. Based on Finnish Population Register Centre data, all the 70 patients were alive 6 years after the initial visit; they received the same questionnaire in October 2015, and if necessary, again in November 2015.

An Ethics Committee, Department of Surgery, of Helsinki and Uusimaa Hospital District approved the study protocol.

\section{Statistical analysis}

Testing of age distribution between genders was by the independent samples $t$ test, as were differences in age between respondents and non-respondents, and gender distributions by the Pearson Chi-square test. The difference in DHI and subjective outcome between 3 and 6 years of follow-up was tested by the Wilcoxon signed rank test. The Chi-squared test served for comparison of subjective outcome between those who had a specific cause for globus and those who did not. Tests were two-tailed, and significance was set at 0.05 . All computations were by the Statistical Program for Social Sciences (SPSS for Windows, Version 22.0 statistical software; SPSS Inc, Chicago, IL).

\section{Results}

\section{Patient characteristics}

Of the 76 globus patients, 59 (78 \%) were female. At their initial visit in 2009 , the patients' median age was 49.5 (range 20-88), with age distribution similar by gender. According to medical records, 11 patients $(14 \%)$ either had some psychiatric diagnosis or took a selective serotonin reuptake inhibitor (SSRI). These 11 included 7 patients with depression, one suffering from a panic disorder and one from bipolar disorder. In the other two, the indication for SSRI medication was unclear.

\section{Examinations and findings}

All patients underwent a clinical ENT examination at our department, including neck palpation. Neck ultrasound was performed in 37 patients, for 23 of whom, it was performed before referral to an ENT clinic. All six gastroscopies were performed before referral. Examinations scheduled at the ENT clinic included videofluorography (VFG), transnasal esophagoscopy (TNE), and neck ultrasound (Table 2).

\section{Causes for globus symptom}

Retrospective analysis of medical records revealed the ENT physician's opinion of the suspected cause for the globus symptom in $44(58 \%)$. The most common suspected cause was dry mucous membranes, evident in 13 (17\%) 
Table 1 The Deglutition Handicap Index

\begin{tabular}{|c|c|c|c|c|c|}
\hline & $\mathrm{N}$ & AN & $\mathrm{S}$ & AA & A \\
\hline I feel a discomfort when I swallow & 0 & 0 & 0 & 0 & 0 \\
\hline The food sticks or stays blocked in my throat & 0 & 0 & 0 & 0 & 0 \\
\hline I have difficulty swallowing liquids & 0 & 0 & 0 & 0 & 0 \\
\hline I cough or clear my throat during or after a meal & 0 & 0 & 0 & 0 & 0 \\
\hline I suffocate when eating of drinking & 0 & 0 & 0 & 0 & 0 \\
\hline I feel food or liquid coming up after a meal & 0 & 0 & 0 & 0 & 0 \\
\hline I have difficulty chewing & 0 & 0 & 0 & 0 & 0 \\
\hline Food comes up to my nose when I drink or eat & 0 & 0 & 0 & 0 & 0 \\
\hline I dribble when I eat & 0 & 0 & 0 & 0 & 0 \\
\hline My throat hurts when I swallow & 0 & 0 & 0 & 0 & 0 \\
\hline I am unable to eat certain foods because of my swallowing difficulties & 0 & 0 & 0 & 0 & 0 \\
\hline I have to modify the consistency of the food in order to swallow & 0 & 0 & 0 & 0 & 0 \\
\hline It takes longer to eat a meal because of my swallowing difficulties & 0 & 0 & 0 & 0 & 0 \\
\hline I eat less because of my swallowing problems & 0 & 0 & 0 & 0 & 0 \\
\hline I am still hungry or thirsty after a meal & 0 & 0 & 0 & 0 & 0 \\
\hline I am tired because of my swallowing problems & 0 & 0 & 0 & 0 & 0 \\
\hline I have lost weight because of my swallowing difficulties & 0 & 0 & 0 & 0 & 0 \\
\hline I am afraid of eating & 0 & 0 & 0 & 0 & 0 \\
\hline I have had bronchitis or pulmonary infections more often since my swallowing problems & 0 & 0 & 0 & 0 & 0 \\
\hline I have more trouble breathing since my swallowing problems & 0 & 0 & 0 & 0 & 0 \\
\hline I avoid eating with others because of my swallowing difficulties & 0 & 0 & 0 & 0 & 0 \\
\hline My swallowing problem limits my personal or social life & 0 & 0 & 0 & 0 & 0 \\
\hline I am bothered by the way I eat during meal & 0 & 0 & 0 & 0 & 0 \\
\hline Eating has become a disagreeable time because of my swallowing problems & 0 & 0 & 0 & 0 & 0 \\
\hline I find that others do not understand my swallowing problems & 0 & 0 & 0 & 0 & 0 \\
\hline Others seems to be irritated by my swallowing problems & 0 & 0 & 0 & 0 & 0 \\
\hline I am tense when I eat with others because of my swallowing & 0 & 0 & 0 & 0 & 0 \\
\hline I am ashamed of my swallowing problem & 0 & 0 & 0 & 0 & 0 \\
\hline I feel handicapped because of my swallowing difficulties & 0 & 0 & 0 & 0 & 0 \\
\hline Total & & & & & \\
\hline
\end{tabular}

$N$ never, $A N$ almost never, $S$ sometimes, $A A$ almost always, $A$ always

Table 2 Examinations and findings in 76 globus patients

\begin{tabular}{lccl}
\hline & Performed $N(\%)$ & Normal $N(\%)$ & Abnormal $N(\%)$ \\
\hline Neck ultrasound & $37(49)$ & $36(97)$ & $1(3)^{\mathrm{a}}$ \\
Videofluorography & $22(29)$ & $20(91)$ & $2(9)^{\mathrm{b}}$ \\
Gastroscopy & $6(8)$ & $5(83)$ & $1(17)^{\mathrm{c}}$ \\
Transnasal esophagoscopy & $1(1)$ & $1(100)$ & 0 \\
\hline
\end{tabular}

a Goiter

b Slightly abnormal findings, such as minor residual contrast medium

${ }^{c}$ Duodenal ulcus

(Table 3). The median age of these patients was 56 (range 31-68). Based on medical records, videolaryngostroboscopy was performed in 24 patients ( $32 \%$ ), others were examined using a nasofiberoscope or a mirror. ENT physicians suspected that five globus patients had a concomitant voice disorder, possibly also causing globus (Table 3 ).

\section{Treatment}

The majority of patients received only support and reassurance during their outpatient visit. Patients with dry mucous membranes were instructed to drink enough water and to humidify the inhaled air. In a trial of whether silent 
Table 3 Clinicians' evaluation of suspected cause for globus in 76 patients

\begin{tabular}{lc}
\hline & $N(\%)$ \\
\hline Unknown cause & $32(42)$ \\
Dry mucous membranes & $13(17)$ \\
Muscle tension in the neck & $12(16)$ \\
Psychological cause & $6(8)$ \\
Problems with voice & $5(7)$ \\
Lingual tonsil hypertrophy & $3(4)$ \\
Epiglottis in contact with adjacent structures & $3(4)$ \\
Goiter & $1(1)$ \\
Sequela after acoustic neurinoma surgery & $1(1)$ \\
\hline
\end{tabular}

reflux was a cause of globus, 22 patients $(29 \%)$ received a PPI prescription, even though they had no heartburn. One bupropion medication was prescribed to support quitting smoking. Three patients met with a speech and language pathologist (SLP), and two other patients received referrals to physiotherapist. One patient had a palpable goiter confirmed by neck ultrasound. She was referred to surgical evaluation and thyroid lobectomy alleviated her globus symptom.

\section{Three-year follow-up}

After the 3-year follow-up, we received questionnaires concerning their present pharyngeal symptoms from 37 globus patients $(53 \%)$, of whom, 28 (76\%) were female; median age was 57.0 (range 24-83). Mean age and gender distribution between those returning the questionnaire and not doing so was similar. The patients' median score in DHI was 7.0 (range 0-71). Total DHI was elevated in six patients $(17 \%)$. Patients' answers to the question whether they are symptomatic after 3 years are presented in Table 4.

\section{Six-year follow-up}

In 2015, after a minimum 6-year follow-up, we sent out another questionnaire and received a response from 27 globus patients (39\%), of which 23 were female (85\%); median age was 60 (range 35-86). Again, age and gender distribution between those answering and not answering did not differ. Of these 27 patients, $22(81 \%)$ had returned the questionnaire also in 2012, and we had the results of 21 patients' DHI and 19 patients' subjective outcome after both 3 and 6 years of follow-up. After 6 years, the median on the DHI was 5.0 (range 0-51); total DHI was abnormal in four patients $(15 \%)$. Patients' answers to the current status of their globus symptom after 6 years are presented in Table 4. No statistically significant differences appeared in globus patients' DHI $(p=0.574)$ or subjective outcome $(p=0.317)$ between 3 and 6 years of follow-up. Subjective outcome after $3(p=0.958)$ and 6 years $(p=0.656)$ did not significantly differ between those having a suspected cause for globus at the initial visit, and all the others. To calculate this, patients who had no symptoms were compared to the total amount of patients who reported any symptoms (less symptoms, unchanged symptoms, or worse symptoms).

\section{Finnish Cancer Registry data}

According to Finnish Cancer Registry data, none of the globus patients, during the 3-year follow-up, developed any head and neck malignancy. However, one patient had a finding of small goiter nodules in neck ultrasound before referral to an ENT clinic in 2009. She also felt pain upon palpation of her thyroid cartilage. The magnetic resonance imaging prescribed at the ENT clinic in 2009 was unsuccessful because of her panic disorder. In 2013, she felt a palpable tumor in her neck, later revealed to be papillary thyroid cancer.

\section{Discussion}

Neck ultrasound was the most frequently performed radiological examination. Although half our patients underwent it, the examination provided significant information in only one patient with palpable goiter. Patients without abnormal neck palpation findings thus seem seldom to benefit from neck ultrasound. One-third underwent videofluorography. This examination has been adapted from the barium swallow study modifying it with different liquids and solids to evaluate the swallowing process and to identify the cause for swallowing difficulty. Based on medical records, in most cases the ENT physician's decision to perform further investigations was unclear. Perhaps one indication for videofluorography was evaluation of UES pressure or UES dysfunction. A study with conventional manometry found that UES pressure was elevated more frequently in globus patients than in controls [5]. Recently, a prospective study showed globus patients with no elevated UES pressure as measured by more accurate method, high-resolution manometry [4]. Nevertheless, in our study, videofluorography did not provide any further information about the symptom: one elderly female patient had slight difficulties in bolus control and another had a minor residual of contrast medium. Otherwise the results were normal and none of the patients had cricopharyngeal dysfunction. Accordingly, our result is in line with previous report, which has shown other radiographic swallow examinations, modified barium swallow study, and 
Table 4 Patients' reported symptoms after 3 and 6 years of follow-up

\begin{tabular}{lcc}
\hline & 3 Years & 6 Years \\
\hline Number of answers $^{\mathrm{a}}$ & $29(38 \%)^{\mathrm{b}}$ & $27(39 \%)$ \\
No symptoms & $11(38 \%)$ & $12(44 \%)$ \\
Less symptoms & $5(17 \%)$ & $2(7 \%)$ \\
Unchanged symptoms & $11(38 \%)$ & $13(48 \%)$ \\
More difficult symptoms & $2(7 \%)$ & $0(0)$ \\
\hline Questionnaire was sent to 70/76 patients available for the study & \\
a Some patients returned the questionnaires only 3 or 6 years after their initial visit & \\
b Eight patients excluded who had not answered this question or with an answer not interpretable
\end{tabular}

esophagram, to be of limited value in globus diagnostics [9].

Finnish Cancer Registry data confirmed that in this series, globus was not an early symptom of malignancy. In a study of Rowley et al. none of their 74 globus patients developed upper aerodigestive tract malignancies during a 7-year follow-up. In that study, a questionnaire went out 7 years after the initial visit, and symptomatic respondents received invitations to re-examinations to rule out malignancy. Since these data were not based on any national cancer registry, some cancer cases may have been missed [10]. Accordingly, globus may raise concern in both the patient and the ENT physician about possible malignancy causing the symptom. This may often lead to further examinations. Consequently, another possible reason for performing neck ultrasound and videofluorography in our study may have been the ENT physician's need to convince the patient that globus is harmless. Common options for management of globus patients are explanation of the potential causes for the symptom and reassurance that it is not associated with any severe disease [2]. In addition, when ENT status including neck palpation is normal, and the patient shows no alarming signs such as weight loss and progressive dysphagia, no further investigations are usually recommended [2].

Responses to our questionnaire 3 and 6 years after the initial visit revealed that approximately half the patients were asymptomatic, or had fewer symptoms, findings in line with those of other studies [10,11]. Male gender and short duration of globus symptoms have been associated with rapid resolution of symptoms [11]. As our study was retrospective, duration of symptoms before the initial visit remained unassessable, and other factors predicting the persistence of symptoms in individual patients remained unidentifiable. ENT physician's possible assessment of suspected cause for globus at the initial visit could not predict patients' subjective outcome after 3 or 6 years' follow-up. Scores in DHI were low, and globus patients had mainly normal results both in 2012 and 2015. The DHI is a validated, self-administered quality-of-life questionnaire, which contains physical, functional and emotional subscales concerning deglutition [8]. As the DHI is directed to dysphagia patients, our patients' low scores indicate that most globus patients did not suffer from any swallowing difficulties.

We retrospectively investigated whether ENT physicians suspected any specific cause for patients' globus symptoms. In almost half the patients, no cause was identifiable, and they received mainly support and reassurance during their outpatient visit. The most common cause or contributing factor for sensation of a lump in the throat was considered to be dry mucous membranes. Globus may be associated with other throat symptoms, such as throat irritation, dryness, or excessive throat clearing. Muscle tension and voice disorders affected over $20 \%$ of our patients. Contraction of the strap muscles of the neck as a possible cause for globus was already described in the early eighteenth century [12]. For some globus patients, an SLP's treatment is beneficial [13]. In this series, a psychological factor such as stress may have been a contributing factor in $8 \%$. Severe life events occurring 1 year before globus onset seemed to affect patients with globus more often than they do controls, [6] and globus patients were significantly more depressed than controls in one case-control series [14]. Depression was the diagnosis in at least $9 \%$ of our patients, quite similar compared to the rate in Finland's general population (6\%) [15]. In one study from the 1990s, the proportion of globus patients with a psychiatric diagnosis did not differ from that of the general population [16].

The patient with a palpable goiter confirmed by neck ultrasound became asymptomatic after thyroid lobectomy. One-third of patients with a thyroid mass such as goiter may have a globus-like symptom, but after thyroid surgery are expected to experience improvement, [17] difficult to attribute to surgery or to spontaneous recovery. Moreover, thyroid nodules larger than $3 \mathrm{~cm}$ located anterior to the trachea have had a tendency to cause globus symptoms [18]. One of our globus patients had a couple of goiter nodules sized less than $1 \mathrm{~cm}$ diagnosed in neck ultrasound in 2009. Four years later, a tumor was palpable and further examination revealed thyroid cancer. But as the authors 
concluded, the association between small thyroid nodules and globus sensation is unlikely [18].

Lingual tonsil hypertrophy was the suspected cause for globus in three of our patients (4\%). In cases with severe tongue-base hypertrophy, symptoms may include globus [19]. For three of our patients (4\%), their symptom was possibly connected to the epiglottis touching the tonguebase or posterior pharyngeal wall. One small series of globus patients having the epiglottis touching the tonguebase felt asymptomatic after partial epiglottectomy by $\mathrm{CO}_{2}$ laser, [20] but that study included no controls, so the operation may have had a placebo effect. One of our patients felt a globus sensation postoperatively after acoustic neurinoma surgery. It is possible that airway manipulation during intubation caused her pharyngeal symptom.

Our study has some limitations. Globus patients presenting with an obvious finding in clinical examination were not recorded with the ICD-10 code F45.8. However, these patients do not offer the same diagnostic challenge, as do patients with no clinical findings. This being a retrospective study, some medical records were incomplete, and the ENT physician's opinion of the suspected cause for globus was sometimes lacking, as was the reason for further investigations. Moreover, follow-up data on symptom persistence were unavailable for half the patients. Unfortunately, no information is available on the incidence of malignancy at the 6-year follow-up, since the Finnish Cancer Registry data are published with a delay.

Sometimes globus and reflux symptoms occur simultaneously. However, if PPI relieves the symptoms, the symptom is a sign of GERD, and diagnosis of globus is inaccurate [21]. Some of our patients had a PPI prescription before their referral, despite having no reflux symptoms. Since they received no benefit from the medication, they were referred to the ENT clinic. Furthermore, following their clinical examination, $29 \%$ of patients without reflux symptoms still received a PPI prescription at ENT clinic. Whether globus patients have GERD has been debated, but it seems that globus patients without any reflux symptoms seldom have GERD and, accordingly, gain no benefit from PPI medication [4].

\section{Conclusion}

In this work we studied possible benefit of neck ultrasound and videofluorography in globus diagnostics. Globus patients without clinical findings did not benefit of these examinations. Thus, neck ultrasound and videofluorography are not recommended to use in clinical routine. In this study we did not focus on therapeutic issues or benefits of follow-up. However, regarding to malignant transformation, follow-up was not needed. Over half the patients were asymptomatic or had fewer symptoms after 3 years, indicating that globus symptoms may resolve spontaneously. After 6 years, however, half the patients were still experiencing persistent symptoms, revealing that globus may be a chronic cause of discomfort.

Acknowledgments We thank the Finnish Cancer Registry for the data they provided and Jaana Koski-Alhainen and Ella Aaltonen for technical assistance.

\section{Compliance with ethical standards}

Funding This study was funded by Helsinki University Hospital Research Funds (EVO), Grant number TYH2013201.

Conflict of interest Each author discloses no conflict of interest.

Ethical approval All procedures performed in studies involving human participants were in accordance with the ethical standards of the institutional and/or national research committee and with the 1964 Helsinki declaration and its later amendments or comparable ethical standards.

Informed consent Informed consent was obtained from all individual participants included in the study.

\section{References}

1. Moloy PJ, Charter R (1982) The globus symptom. Incidence, therapeutic response, and age and sex relationships. Arch Otolaryngol 108:740-744

2. Galmiche JP, Clouse RE, Balint A, Cook IJ, Kahrilas PJ, Paterson WG, Smout AJ (2006) Functional esophageal disorders. Gastroenterology 130:1459-1465

3. Cook IJ (2013) Globus pharyngis. In: Shaker R, Belafsky P, Postma G, Easterling C (eds) Principles of deglutition. Springer, New York, pp 449-460

4. Nevalainen P, Walamies M, Kruuna O, Arkkila P, Aaltonen LM (2016) Supragastric belch may be related to globus symptom-a prospective clinical study. Neurogastroenterol Motil 28:680-686

5. Corso MJ, Pursnani KG, Mohiuddin MA, Gideon RM, Castell JA, Katzka DA, Katz PO, Castell DO (1998) Globus sensation is associated with hypertensive upper esophageal sphincter but not with gastroesophageal reflux. Dig Dis Sci 43:1513-1517

6. Harris MB, Deary IJ, Wilson JA (1996) Life events and difficulties in relation to the onset of globus pharyngis. J Psychosom Res 40:603-615

7. Harar RP, Kumar S, Saeed MA, Gatland DJ (2004) Management of globus pharyngeus: review of 699 cases. J Laryngol Otol 118:522-527

8. Woisard V, Lepage B (2010) The "Deglutition Handicap Index" a self-administrated dysphagia-specific quality of life questionnaire: temporal reliability. Rev Laryngol Otol Rhinol (Bord) 131:19-22

9. Dworkin JP, Dowdall JR, Kubik M, Thottam PJ, Folbe A (2015) The role of the modified barium swallow study and esophagram in patients with globus sensation. Dysphagia 30:506-510

10. Rowley H, O'Dwyer TP, Jones AS, Timon CI (1995) The natural history of globus pharyngeus. Laryngoscope 105:1118-1121 
11. Timon C, O’Dwyer T, Cagney D, Walsh M (1991) Globus pharyngeus: long-term follow-up and prognostic factors. Ann Otol Rhinol Laryngol 100:351-354

12. Purcell J (1707) A treatise of vapours or hysterick fits. Edward Place, London

13. Khalil HS, Bridger MW, Hilton-Pierce M, Vincent J (2003) The use of speech therapy in the treatment of globus pharyngeus patients. A randomised controlled trial. Rev Laryngol Otol Rhinol (Bord) 124:187-190

14. Deary IJ, Smart A, Wilson JA (1992) Depression and 'hassles' in globus pharyngis. Br J Psychiatry 161:115-117

15. Ferrari AJ, Charlson FJ, Norman RE, Patten SB, Freedman G, Murray CJ, Vos T, Whiteford HA (2013) Burden of depressive disorders by country, sex, age, and year: findings from the global burden of disease study 2010. PLoS Med 10:e1001547

16. Farkkila MA, Ertama L, Katila H, Kuusi K, Paavolainen M, Varis K (1994) Globus pharyngis, commonly associated with esophageal motility disorders. Am J Gastroenterol 89:503-508
17. Burns P, Timon C (2007) Thyroid pathology and the globus symptom: are they related? A two year prospective trial. J Laryngol Otol 121:242-245

18. Nam IC, Choi H, Kim ES, Mo EY, Park YH, Sun DI (2015) Characteristics of thyroid nodules causing globus symptoms. Eur Arch Otorhinolaryngol 272:1181-1188

19. Mamede RC, De Mello-Filho FV, Dantas RO (2004) Severe hypertrophy of the base of the tongue in adults. Otolaryngol Head Neck Surg 131:378-382

20. Agada FO, Coatesworth AP, Grace AR (2007) Retroverted epiglottis presenting as a variant of globus pharyngeus. J Laryngol Otol 121:390-392

21. Kahrilas PJ, Smout AJ (2010) Esophageal disorders. Rev Gastroenterol Mex 75:453-462 